\title{
Qualidade da atenção ao pré-natal: olhares de adolescentes puérperas
}

\author{
Francisco Rosemiro Guimarães Ximenes Neto, M.Sc.*, Samuel Moreira Macedo**, José Rocha, M.Sc.**, \\ Isabel Cristina Kowal Olm Cunha, D.Sc.***
}

\begin{abstract}
*Enfermeiro Sanitarista, Docente do Curso de Enfermagem da Universidade Estadual do Vale do Acaraú - UVA e Preceptor de Enfermagem da Residência em Saúde da Família da Escola de Formação em Saúde da Família, Sobral, Ceará. Membro do Gepag/UNIFESP, **Enfermeiro, Graduado pela UVA, ${ }^{* * *}$ Enfermeiro, Gerente do SAMU da Zona Leste de São Paulo, Membro do Gepag/UNIFESP, São Paulo, *** Enfermeira, Professora Adjunta e Lider Grupo de Estudos e Pesquisas em Administração em Saúde e Gerenciamento de Enfermagem-GEPAG da Universidade Federal de São Paulo-UNIFESP, Sáo Paulo, SP
\end{abstract}

\section{Resumo}

A atenção ao pré-natal na Estratégia Saúde da Família (ESF) visa à promoção/manutenção da saúde e prevenção de doenças decorrentes e intercorrentes da gravidez. Este estudo é do tipo exploratório-descritivo, com abordagem qualitativa, e tem como objetivos analisar a percepção das puérperas adolescentes acerca da atenção ao pré-natal e descrever seu perfil sóciodemográfico e obstétrico. A pesquisa foi realizada no território da ESF do Bairro Sumaré, em Sobral-Ceará, com oito puérperas adolescentes. Para a coleta de dados - em janeiro de 2007 - foram utilizados, um formulário e uma entrevista semi-estruturada. Os resultados apresentam o seguinte perfil: a faixa etária das adolescentes era de 15 a 19 anos, seis tinham renda familiar de um salário mínimo, quatro com ensino médio - completo ou incompleto -, todas com parceiro fixo e gesta - um -, apenas uma teve parto cesariano e nenhuma havia abortado e, quanto ao número de consultas pré-natais, variou entre seis e doze. Quanto à percepçáo acerca do pré-natal, as puérperas relataram ser importante para se avaliar a saúde materna e fetal, sendo essencial para o desenvolvimento e nascimento deste. Ratificaram ainda, ter vivenciado um período de aprendizados, através da educação em saúde e dos exames realizados pelos profissionais de saúde, que tiveram unanimidade de aprovaçáo por elas. Por meio dos resultados, percebemos a necessidade de que a comunidade reconheça os benefícios que a atençáo ao pré-natal proporciona às mães e a seus filhos.

Palavras-chave: cuidado pré-natal, adolescente, período pós- parto, percepção.

\section{Abstract \\ Quality of prenatal care from postpartum adolescents point of view}

The prenatal care in the Family Health Strategy (FHS) aims to provide health promotion/management and prevention of current and intercurrent pregnancy diseases. This exploratory and descriptive study, with qualitative approach, has as objectives to analyze the perception of postpartum adolescents concerning prenatal care and to describe their socio-demographic and obstetric profile. The research was carried out in the FHS territory of Sumaré neighborhood, in Sobral - Ceará, with eight 
postpartum adolescents. Data was collected in January 2007, using a form and a semistructured interview. The results show the following profile: adolescents age group was from 15 to 19 years, six had family income of a minimum wage, four had High School (complete or incomplete), all of them had a steady relationship and first pregnancy, just one underwent Caesarean section, none of them had an abortion, and the number of prenatal visits varied from six to twelve. Regarding prenatal perception, postpartum adolescents reported to be important the evaluation of maternal and fetal health, as it is essential for fetal development and birth. They also ratified the acquired knowledge during this period, through health education and also clinical exams carried out by health professionals, which got a unanimous approval. The results showed the community recognition need of the benefits that prenatal care provides to mothers and their children.

Key-words: prenatal care, adolescent, postpartum period, perception.

\section{Resumen \\ Calidad de la atención prenatal: desde el punto de vista de adolescentes puérperas}

La atención prenatal en la Estrategia Salud de la Familia (ESF) busca la promoción/ mantenimiento de la salud y prevención de enfermedades provenientes y interrecurrentes del embarazo. Este estudio exploratorio-descriptivo de naturaleza cualitativo tiene como objetivos analizar la percepción de las puérperas adolescentes acerca de la atención prenatal y describir su perfil socio-demográfico y obstétrico. La investigación fue realizada en el territorio de la ESF en el Barrio Sumaré, en Sobral - Ceará, con ocho puérperas adolescentes. Para la colecta de datos, en Enero de 2007, fueron utilizados un formulario y una entrevista semi-estructurada. Los resultados presentan el siguiente perfil: predominó el grupo de edad de las adolescentes entre 15 y 19 años; seis tenían renta familiar de un salario mínimo, cuatro tenían enseńanza media - completa o incompleta -, todas con compañero fijo y primer hijo, siendo que apenas una tuvo parto por cesárea y ninguna había abortado, cuanto al número de visitas de atención prenatal, este varió entre seis y doce. Con relación a la percepción acerca del prenatal, las puérperas relataron ser importante para evaluar la salud materna y fetal, siendo esencial para el desarrollo y nacimiento de este. Ratificaron todavía, haber experimentado un periodo de aprendizaje, a través de la educación en salud y de los exámenes realizados por los profesionales de salud, que tuvieron la aprobación unánime de todas. Por medio de los resultados, percibimos la necesidad de que la comunidad reconozca los beneficios que la atención prenatal proporciona a las madres y a sus hijos.

Palabras-clave: atención prenatal, adolescente, periodo de postparto, percepción.

\section{Introdução}

A adolescência é uma fase do ciclo de vida do ser humano em que ocorrem alteraçóes de caráter psicológico e anátomo-fisiológicas. Segundo $\mathrm{Ca}$ dete " [...] estar adolescente [...] entrar no mundo, mudar mentalidade, o corpo, viver ambigüidades, viver uma fase ruim, ter mais responsabilidade e ter abertura da perspectiva de futuro" [1:20]. A adolescência, segundo Saito, deve "ser encarada como uma etapa crucial e bem definida do processo de crescimento e desenvolvimento, cuja marca registrada é a transformação ligada aos aspectos físicos e psíquicos do ser humano, inserido nas mais diferentes culturas" [2:33].

A adolescência é um período da vida que compreende o ser humano dos 10 aos 19 anos, que vai muito além de uma faixa etária, inserindo, portanto, uma fase de transformaçóes e adaptaçóes biológicas, mentais, psicológicas e de ajustes e aceitação social e cultural.
No processo do adolescer, além dos conflitos próprios dessa fase de transformação orgânica, o ser humano se depara com o sexo e as drogas; o primeiro (o sexo) devemos considerá-lo como algo inerente e próprio do ser humano, que deve ser vivido de forma intensa e com responsabilidades, para que não se tenha aquisição de algum tipo de Doença Sexualmente Transmissível-DST, HIV/ AIDS, como também uma gravidez; e o segundo, a prática do uso e abuso de drogas, como algo que impede o desenvolvimento do adolescente, destruindo, inclusive os projetos de vida e as relaçóes familiares em alguns casos.

No que concerne ao início da atividade sexual, é crescente o número de adolescentes que estão engravidando. Hoje em dia, a incidência de adolescentes grávidas está cada vez mais freqüente em países em desenvolvimento, principalmente, no Brasil, que a cada ano, segundo dados do Ministério da Saúde, cerca de $20 \%$ dos partos são de adolescentes, sendo que nessa década o número já representa três vezes 
mais adolescentes com menos de 15 anos grávidas que na década de 1970 [3].

Para tanto, os serviços de saúde devem estar equipados e qualificados para acolher tais gestantes adolescentes durante a atenção ao pré-natal. Pois, um pré-natal de qualidade proporciona efeitos satisfatórios a gestante e ao bebê, dentre muitos fatores, temos uma menor taxa de mortalidade materna e perinatal, baixo peso ao nascer e intercorrências durante a gravidez, parto, pós-parto imediato de restante do puerpério.

Com o advento do Programa Saúde da Família em 1994, com a Norma Operacional de Assistência à Saúde NOAS-SUS 01/2001 e a Política Nacional de Humanização da Atenção Pré-natal e ao Parto em 2002, a atenção ao pré-natal vem sendo desenvolvida como uma das açóes prioritárias pelas políticas públicas de saúde, proporcionando um maior impacto no cuidado e promoção da saúde da mulher em todo o ciclo gravídico-puerperal, assegurando que, ao fim da gestação, o parto ocorra com o nascimento de uma criança saudável, e garantindo o bem-estar materno e, ainda, prevenção, controle ou correçáo de anormalidades decorrentes e interferentes na gravidez, além da prevenção de possíveis intercorrências durante o puerpério, seja imediato ou tardio.

Nesse contexto a Equipe de Saúde da Família, desde o Agente Comunitário de Saúde-ACS - na comunidade, com a identificação precoce da gestante e o encaminhamento da mesma ao pré-natal - até os profissionais de saúde pré-natalistas, como o enfermeiro e o médico devem estar qualificados e sensibilizados a uma atenção de qualidade, responsável, holística e humanizadora, principalmente, no que concerne a gestante adolescente.

No caso da gravidez na adolescência, tem sido comum os profissionais de saúde, em sua prática clínica, associarem, geralmente, a mesma à possibilidade de aumento das intercorrências clínicas e morte materna, assim como os índices elevados de prematuridade, mortalidade neonatal e baixo peso ao nascer, entre outras conseqüências, sendo consideradas, então, como gestantes de alto risco. Sendo importante, porém, a captação precoce dessa gestante adolescente, pois, somente a inscrição de uma gestante no Sistema de Informação do Pré-Natal - o SIS-Pré-Natal - não quer dizer que a mesma compreenda a dinâmica e a importância da atenção ao pré-natal e a qualidade do mesmo.
Tal situação motivou alguns questionamentos durante vivências nos territórios da Estratégia Saúde da Família do Município de Sobral-CE em que se pode perceber uma fragilidade das gestantes adolescentes, quanto ao conhecimento em relação ao pré-parto, parto e puerpério. Sendo eles: Qual a percepçáo que as adolescentes puérperas possuem em relação à atenção ao pré-natal recebida? Que contribuiçóes, na perspectiva das adolescentes, o pré-natal proporciona a elas e seus filhos?

Assim, o presente estudo objetiva analisar a percepção das adolescentes puérperas acerca da atenção ao pré-natal e descrever o perfil sóciodemográfico e obstétrico destas.

\section{Material e métodos}

A pesquisa é do tipo exploratório-descritiva constituída por um estudo de caso desencadeado a partir da ansiedade de se saber qual a percepçáo das puérperas adolescentes acerca da atenção ao prénatal, em um determinado território da Estratégia Saúde da Família (ESF). A abordagem utilizada foi qualitativa, pois suas características definidoras apresentam traços deste tipo de pesquisa.

A pesquisa foi realizada com oito adolescentes puérperas assistidas pela ESF do Bairro Sumaré, Sobral-CE. O Ministério da Saúde conceitua como puerpério o período do ciclo grávido-puerperal em que as modificaçóes locais e sistêmicas, provocadas pela gravidez e parto no organismo da mulher, retornam à situação do estado pré-gravídico. O puerpério pode ser didaticamente dividido em: puerpério imediato, que vai do primeiro dia, logo após a dequitação completa da placenta, ao $10^{\circ}$ dia; puerpério tardio, do $11^{\circ}$ ao $42^{\circ}$ dia; e puerpério remoto, a partir do $43^{\circ}$ dia [4].

Para a identificaçáo dos sujeitos do estudo em suas residências, foi de relevante importância a contribuição das ACS. Os dados foram coletados através de um formulário e de uma entrevista semiestruturada. O formulário foi utilizado para coletar os dados do perfil sócio-demográfico e obstétrico das adolescentes puérperas, que são: idade, estado civil, escolaridade, renda familiar, antecedentes obstétricos, mês de gestação na inserção ao pré-natal e o número de consultas realizadas.

$\mathrm{Na}$ entrevista semi-estruturada, para coletar os dados acerca da percepção das puérperas em relação à atenção ao pré-natal, foi utilizado um gravador de 
som, visando um melhor proveito das respostas e economia de tempo.

Os dados estão analisados a partir de categorias, que Gomes sugere sua utilização para o estabelecimento de classificaçóes. A autora completa afirmando, que trabalhar com categorias significa "agrupar elementos, idéias ou expressóes em torno de um conceito capaz de abranger tudo isso. Esse tipo de procedimento, de um modo geral, pode ser utilizado em qualquer tipo de análise em pesquisa qualitativa". Ela encerra referindo que "as categorias podem ser estabelecidas antes do trabalho de campo, na fase exploratória da pesquisa, ou a partir da coleta de dados". As categorias "estabelecidas antes são conceitos mais gerais e mais abstratos. Esse tipo requer uma fundamentação teórica sólida por parte do pesquisador. Já as formuladas a partir da coleta de dados são mais específicas e mais concretas" [5:70]. Para não expor as puérperas e preservar a integridade das mesmas, foi dado um nome fictício, de graduandas do Curso de Enfermagem da UVA 2006 [2].

Para a realização do estudo foi solicitada, inicialmente, a permissão da Secretaria da Saúde e Ação Social do Município de Sobral-CE, por meio da Comissão Científica, quando foi encaminhado o Protocolo de Pesquisa, sendo o mesmo analisado e aprovado. Durante todas as fases da pesquisa foram respeitados os aspectos éticos e legais da pesquisa, conforme o emanado pela Resolução No 196/1996 do Conselho Nacional de Saúde-CNS [6].

\section{Resultados e discussão}

\section{Perfil das puérperas}

Gilcélia, 17 anos; com parceiro fixo; escolaridade: cursa o primeiro ano do ensino médio; renda familiar mensal de um salário mínimo*; Gesta 1, Para 1, Aborto 0; iniciou pré-natal no primeiro trimestre de gravidez, segundo mês, totalizando seis consultas.

Rafaella, 18 anos; com parceiro fixo; cursa o primeiro ano ensino médio; renda familiar mensal de dois salários mínimos*; Gesta 1, Para 1, Aborto 0; iniciou pré-natal no segundo trimestre de gravidez, quinto mês, totalizando nove consultas.

Aurealice, 18 anos; com parceiro fixo; escolaridade: cursa a sétima série do ensino fundamental; renda familiar de aproximadamente três salários mínimos*; Gesta 1, Para 1, Aborto 0; iniciou pré-natal no primeiro trimestre, segundo mês, totalizando 12 consultas.

Bruna, 15 anos; com parceiro fixo; escolaridade: cursa a sexta série do ensino fundamental; renda familiar de um salário mínimo*; Gesta 1, Para 1, Aborto 0; iniciou pré-natal no primeiro trimestre, terceiro mês, totalizando nove consultas.

Antonielle, 19 anos; com parceiro fixo; escolaridade: primeiro ano do ensino médio, completo; renda familiar de um salário mínimo*; Gesta 1, Para 1 , Aborto 0 ; iniciou pré-natal no primeiro trimestre, terceiro mês, totalizando sete consultas.

Germana, 19 anos; com parceiro fixo; escolaridade: cursa a sexta série do ensino fundamental; renda familiar de um salário mínimo*; Gesta 1, Para 1, Aborto 0; iniciou pré-natal no primeiro trimestre, terceiro mês, totalizando nove consultas.

Gabriela, 17 anos; com parceiro fixo, mora com a mãe; escolaridade: ensino médio completo; renda familiar de um salário mínimo*; Gesta 1, Para 1, Aborto 0; iniciou pré-natal no primeiro trimestre, primeiro mês, totalizando 10 consultas.

Allany, 15 anos; com parceiro fixo; escolaridade primeiro ano do ensino médio, completo; renda familiar de um salário mínimo*; Gesta 1, Cesáreo 1, Aborto 0; iniciou pré-natal no primeiro trimestre, segundo mês, totalizando doze consultas.

*O valor do salário mínimo em janeiro de 2007 era de R \$ 350,00 equivalendo a US\$ 162,80- US\$ $1,00=\mathrm{R} \$ 2,15$.

As puérperas do estudo estão na faixa etária entre 15 e 19 anos. Este período é o de maior progressão nos estudos, de se pensar em ingressar na universidade, qual profissão exercerá, há, então, um hiato social na vida do adolescente, seja ele na maternidade ou paternidade. No caso da adolescente, uma gravidez nessa fase da vida levará a uma possível interrupção dos planos, projetos, enfim os sonhos da construção de uma vida profissional.

Atualmente, estima-se que mulheres com idade entre 10 e 19 anos respondam por cerca de 23 a 30\% do total das gestaçôes [7].

A renda familiar varia de um a três salários mínimos por família, sendo que, a renda familiar de seis puérperas é referente a um salário mínimo. Dividida a renda pelo número de pessoas do domicílio, perfaz uma renda média de $\mathrm{R} \$ 84,00$ para cada pessoa sobreviver mensalmente.

Segundo o IBGE, em 2001, no Brasil, 35\%, das 27,3 milhóes de famílias que ainda tinham um membro com até 14 anos de idade, - 9,5 milhóes 
de famílias - viviam com um rendimento mensal familiar per capita de $1 / 2$ salário mínimo. A região Nordeste se destacava com $57 \%$ de famílias nesse patamar. A renda familiar contribui significativamente para uma melhor ou pior qualidade de saúde, pois o poder aquisitivo implica potencialmente na alimentação, habitação, higiene, transporte e outros fatores socioeconômicos de influência potencial em saúde [8].

No quartil de menor renda, 35\% das mulheres latino-americanas têm seu primeiro filho antes dos 20 anos de idade; enquanto no quartil superior estes casos náo chegam a $10 \%$. As diferenças são ainda mais fortes quando se analisa o nível educacional das mulheres. Quase metade das puérperas não completa o ensino fundamental, pois foram mães adolescentes, contra apenas 7\% das que completam o ensino médio [8]. Por isso, a relaçáo entre a maternidade na adolescência e a pobreza traz à tona graves problemas, como taxas de mortalidade infantil elevada, desnutrição materno-infantil e outras carências comuns à infância brasileira.

No Brasil, é no estrato social mais pobre que se encontra o maior índice de fecundidade na população adolescente. Conforme dados do Ministério da Saúde (2000), no estrato de renda familiar menor de um salário mínimo, observou-se que $26 \%$ das adolescentes entre 15 e 19 anos tinham filhos, e no estrato mais elevado, somente $2,3 \%$ eram mães. Quanto à escolaridade, apenas uma das puérperas havia terminado o ensino médio; quatro cursavam o primeiro ano do ensino médio e três, cursavam o ensino fundamental, quando interromperam os estudos por causa da gravidez $[4,9,10]$.

Segundo o Instituto Brasileiro de Geografia e Estatística (IBGE), no censo demográfico de 2000, as mulheres com maior escolaridade - oito anos ou mais - tinham, em média, 1,7 filhos, e com menos de quatro anos de estudo tinham 3,7 filhos. Essa influência da escolaridade na fecundidade é observada em todas as regióes [8].

O Relatório da Situação Mundial da Infância de 2004 diz que educar uma menina significa educar uma família e, conseqüentemente, uma comunidade, uma sociedade e um país. Entretanto, a maioria dessas meninas não recebeu a educação de qualidade a que tem direito e, quando adultas, não estarão aptas a participarem do desenvolvimento sócio-econômico e político comunitário, estando mais expostas à pobreza juntamente com seus filhos [11].
Um dos grandes desafios para os aparelhos sociais dos territórios da ESF é fazer com que as adolescentes que evadiram das salas de aula por conta da gravidez, regressem a estas. Nesse caso há, então, um dever social da comunidade e dos profissionais de educação, de saúde, de outras áreas de proteçáo social, além do principal ente, que é a família, e, por conseguinte, os pares destas adolescentes, que atuarão na motivação das mesmas.

Quanto aos fatores de risco gestacional, o Ministério da Saúde aponta as características individuais e as condiçóes sócio-demográficas desfavoráveis da mulher, dentre elas: idade menor que 17 anos, estresse, situação conjugal insegura, baixa escolaridade e condiçôes ambientais desfavoráveis, todas potencialmente presentes na gravidez na adolescência [9].

Quanto ao estado civil, todas as adolescentes do estudo apresentavam parceiro fixo. Sendo que, em sua maioria - sete - ainda moravam com os pais ou avós, dependendo do salário destes para sobrevivência e manutenção de seus cuidados durante a gestação.

Conforme o IBGE, entre 1991 e 2001, houve redução de 4,5\% no número anual de casamentos realizados no registro civil no Brasil. A taxa de nupcialidade legal - obtida pela divisão do número de casamentos pelo de habitantes com mais de 15 anos de idade, multiplicado por mil - no país, que em 1990 era de 7,5 casamentos por mil habitantes com mais de 15 anos, baixou para 5,7 por mil em 2001 [8].

A questáo de a mulher ter ou não um companheiro influencia no seu modo de planejar seus objetivos e sentido de vida, e na sua motivação para buscar recursos de subsistência [12]. Influencia, ainda, na manutenção de seu autocuidado e de seu filho, além de reduzir a insegurança e os problemas psicoespirituais.

Com referência aos antecedentes obstétricos, todas as puérperas, vivenciaram a primeira gravidez; apenas uma, teve parto cesáreo e nenhuma teve aborto. Com relaçáo ao início em que se teve a inserção no pré-natal, a grande maioria iniciou no primeiro trimestre de gravidez. O número de consultas prénatais variou de seis a doze.

Para um adequado acompanhamento ao prénatal, o Ministério da Saúde preconiza um mínimo de seis consultas, para uma gestação a termo. $\mathrm{O}$ intervalo das consultas deve ser de quatro semanas até a $36^{a}$ semana, quando a gestante deve ser acompanhada a 
cada 15 dias, visando à avaliação da pressão arterial, da presença de edemas, da altura uterina, dos movimentos do feto e dos batimentos cardiofetais [8].

Uma puérpera relatou ter iniciado o pré-natal, no segundo trimestre, quinto mês de gestação. Costa afirma que a grávida adolescente inicia mais tardiamente o acompanhamento pré-natal e termina por fazer um menor número de consultas, quando comparada às mulheres com vinte anos ou mais [13]. Esse fato é coerente com o momento de vida peculiar da adolescente, que geralmente não reconhece a importância de planejar o futuro. No entanto, contrariando a referida autora, a mencionada puérpera foi a 12 consultas de pré-natal, pois há, em Sobral, um plano assistencial às mulheres grávidas que se inserem, tardiamente, a esta atenção à vida reprodutiva da mulher, que termina por fazer um maior número de consultas, visando uma menor probabilidade de problemas gestacionais.

Para uma inserçáo precoce das adolescentes ao pré-natal, é necessário que elas tenham uma boa impressão sobre essa assistência, seus benefícios e responsabilidades, além de compreender o objetivo do pré-natal, entendendo sua importância para sua saúde e de seu filho. Outro fator preponderante é a organizaçáo e sensibilidade da equipe da ESF para identificar e captar essa gestante adolescente o mais breve possível.

\section{Apresentando as categorias abstraídas}

\section{Entendimento de pré-natal}

"Nele a gente sabe como é que a criança tá. Nas consulta a gente escuta o coração, eles medem a barriga da gente, faz ultra-som pra gente ver o sexo da criança, como é que a criança tá, a gente até vê. Dá pra gente saber aproximadamente qual é o dia e o mês que vai nascer a criança, eles falam o que a gente pode tomar, os cuidados que a gente deve ter - não tomar susto, se alimentar bem, tomar muito suco." (Gilcélia)

"Ele é bom pra mim e pra neném." (Antonielle)

"Ele serve pra ajudar a mulher a cuidar dela. Vê se a mulher tá boa, se tá se alimentando bem, se tá tomando os remédios do jeito que ela passou." (Germana)
"É bom pra ela [filha] no caso de ela ficar doente." (Bruna)

"É necessário pra saber como é que tá a saúde da mãe e da criança, se tá evoluindo bem, e tem outras coisas importantes também." (Gabriela)

"Nas consultas a gente sabe muita coisa. Eles ensinam muita coisa quando a gente tá grávida. O que a gente pode fazer e o que não pode. E evita doenças, porque a gente sabe logo se o neném tem alguma coisa." (Aurealice)

"Ele serve pra alertar a gente, porque se a gente não fizer, a gente não vai saber de nada, né? Ele é muito importante pra gente porque a gente aprende muita coisa." (Allany)

Os relatos mostram que as puérperas compreendem o pré-natal que vivenciaram como um ente para promoção e manutenção da saúde, juntas à prevenção de doenças decorrentes e intercorrentes da gravidez. Além desses aspectos da atenção ao pré-natal, as puérperas relataram a importância do exame de ultra-sonografia gestacional e da identificação da data provável do parto.

O Ministério da Saúde preconiza que para uma assistência ao pré-natal de qualidade, a equipe de saúde da família deve oferecer uma educação permanente à população da área, em especial às mulheres, fazendo a detecção precoce das gestantes do território da ESF em que atua e o pronto início do acompanhamento ao pré-natal - que deve ser periódico e contínuo - de todas as mulheres grávidas. Ele deve ser iniciado ainda no primeiro trimestre de gravidez, não podendo a equipe esquecer que a assistência ao pré-natal é o primeiro passo para o parto e nascimento humanizados, e que, essa humanização, está intimamente relacionada com o comportamento de respeito que os profissionais estabelecem com a população. Devem então, os profissionais de saúde, buscar o principal objetivo do pré-natal, que é acolher a mulher desde o início de sua gravidez - período de mudanças anatômicas e psíquicas, que cada gestante vivencia de forma diferente, podendo ocasionar medos, dúvidas, angústias, fantasias ou simplesmente a curiosidade de saber o que está acontecendo no interior de seu corpo [9]. 


\section{Benefícios oportunizados pelo pré-natal}

"A criança se desenvolve mais saudável. Se a criança desenvolve alguma doença, a gente sabe." (Gilcélia)

"Foi muito importante porque eu não entendia nada de pré-natal.” (Rafaella)

"Hoje o meu filho tá com saúde, não tem nada, nenhuma doença; se eu não tivesse feito, hoje ele poderia ter alguma doença." (Aurealice)

"Ela veio com saúde. O pré-natal me ajudou muito até os nove meses." (Bruna)

"Eu náo sabia de nada, pois era o meu primeiro filho. Cuidar bem cuidado, eu acho que ainda náo sei, por causa que a gente vai aprendendo com o tempo, né!." (Germana)

"Eu nunca tinha feito exames demais, aí, eu ficava sabendo se tava tudo bem comigo e com a criança também. e tava tudo bem, que era uma coisa que eu náo sabia. Talvez se eu não tivesse ido às consultas, hoje ela não era saudável, e ela é muito saudável, graças a Deus." (Gabriela)

As falas das adolescentes quanto aos benefícios que a atenção ao pré-natal proporcionou a elas e a seus filhos foram relacionadas à promoção/manutenção da saúde e prevenção de doenças, pelo acompanhamento do desenvolvimento de sua gestação durante os nove meses. Foram realizados exames de rotina e complementares e oferecidos diversos ensinamentos da educação em saúde, proporcionando um maior conhecimento acerca dos cuidados com sua saúde e a do bebê, oportunizando um maior controle sanitário na tentativa da melhoria da qualidade de vida. Entretanto, observou-se ainda a desinformação existente na comunidade sobre os objetivos do pré-natal, exigindo uma maior movimentação dos governos, nacional, estadual e municipal, e da própria sociedade, para uma melhor divulgação, sobre os benefícios que a atenção ao pré-natal proporciona à mãe, ao filho, à família e à própria comunidade, por todos os meios de comunicação, principalmente pelos mais acessados por adolescentes.
O meu pré-natal...

"Foi muito bom. É muito bom o pré-natal [...]. Eu gostei muito de todo mundo lá, dos profissionais que me atenderam." (Gilcélia)

"Eu comecei já no quinto mês porque eu pensava que não tinha muita importância. Náo sabia dos exames, aqueles cuidados todos com a gestante. Eu fui e achei importante. Aí eu pensei: eu vou freqüentar mais. Aí passei mais a ir. Eu gostei dos cuidados. Eu fiz os exames. Aí eu passei a entender mais, né?. $\mathrm{O}$ único exame que eu não fiz foi o da prevenção; mas os outros eu fiz tudinho. Tomei os remédios direitinho. Eu não faltei nenhum dia. Eles só erraram o negócio do dia pra mim ter e eu tive antes. Eu gostei muito do pré-natal. Era pra eu ter ido a muito mais tempo, mas eu achava que náo era táo importante." (Rafaella)

"Foi bom, porque lá [na Estratégia Saúde da Família] eu escutei palestra, tem as consultas pra atender direito a gente. Eu gostei muito de fazer o pré-natal, todas as consultas eu ia. Eu aproveitei bem. Gostei muito dos profissionais de lá." (Aurealice)

"Eu achei importante. Eu gostei do pessoal do posto, eles ensinam as coisas. Mas era pra eu ter ido a mais consultas, aí eu tinha aprendido mais e tava com menos dificuldade agora." (Germana)

"Foi legal. Eu gostei do pré-natal, do pessoal, que atendia a gente bem, deixava a gente bem à vontade Tinha as reuniôes, eu ia e ficava sabendo como era que cuidava mais de criança, que eu não tinha experiência. Eu fiz muitos exames. Fiz de sangue, de urina, ultra-sonografia e, graças a Deus, não teve nenhum problema, deu tudo bem. Eu acho que eu aproveitei bem. È tanto que elas diziam que eu não dava trabalho nenhum na gravidez. Aí, sempre que eu ia elas diziam que tava tudo bem." (Gabriela)

"Eu achei bom. Eu aprendi muita coisa [...]. Elas [as enfermeiras] explicavam como era que a pessoa ia ter, que posição era; como é 
que era pra dar de mamar; tinha as reunióes todo mês com a gente, eles diziam que mudanças estavam acontecendo no corpo da gente, sobre o desenvolvimento do feto, tem também os exames, que eu fiz, explicaram como é que a pessoa passa de adolescente pra ser uma mãe.” (Allany)

Analisando os relatos das vivências de prénatal das adolescentes, foi pontual a satisfaçáo que elas tiveram da atenção que lhes foi prestada. $\mathrm{O}$ acolhimento e as consultas, com seus diversos exames e a educação em saúde, foram novamente mencionadas de forma satisfatória pelas usuárias dessa assistência. Entretanto, observou-se uma falha quanto à busca ativa das gestantes adolescentes para as consultas de pré-natal, pois, uma, somente iniciou a realização das consultas no quinto mês de gravidez, mostrando-nos então, a necessidade de uma maior cobrança dos enfermeiros aos ACS, para que estes eduquem/incentivem mais as gestantes, para que iniciem seu acompanhamento ao pré-natal ainda no primeiro trimestre de gravidez. Permanecendo o desinteresse da mulher grávida, é indicado que o próprio enfermeiro faça visitas domiciliares às gestantes, realizando, se necessário, a consulta de pré-natal em suas residências.

Quanto à atuação dos profissionais da ESF, os resultados apontam a certeza de que a equipe está fazendo um ótimo trabalho junto à populaçáo. Para Mendes, a equipe da ESF e a populaçáo adscrita devem ter um sentimento de co-responsabilidade, em que a população reconhece os serviços de saúde e os utilizam em seu benefício, e a equipe de saúde reconhece sua população, criando-se uma parceria em busca da melhoria da saúde [14].

O trabalho educativo dos profissionais de saúde foi muito mencionado pelas adolescentes puérperas, mostrando-nos sua relevante importância para o conhecimento sobre a manutenção da saúde e prevenção e tratamento de doenças das mães em estudo e de seus filhos.

O Ministério da Saúde orienta que, a equipe deve estar preparada para o trabalho educativo. Entre as diferentes formas de realização desse trabalho, destacam-se: as discussóes em grupo, as dramatizações e outras dinâmicas que facilitam a fala e a troca de experiências entre os componentes do grupo. Os principais temas abordados nessas reuniões são: a importância do pré-natal, sexualidade, modificaçóes corporais e emocionais, aleitamento materno, sinais e sintomas do parto, importância das consultas de puerpério e os cuidados com o recém-nascido [9].

\section{Conclusão}

Esta pesquisa revelou que as adolescentes puérperas estudadas encontravam-se na faixa etária entre 15 e 19 anos e tinham parceiro fixo, entretanto, seis ainda moravam com seus pais, sogros e avós, ainda sendo dependentes sócio-economicamente destes. A renda familiar foi de um salário mínimo para seis das entrevistadas. Quanto à escolaridade, metade das adolescentes, ou seja, quatro, tinham o ensino médio - completo ou incompleto - e interromperam os estudos por causa da gravidez, deixando-nos, então, uma incógnita quanto aos seus respectivos retornos às salas de aula.

O perfil sócio-demográfico das puérperas adolescentes em questão nos impóe a questionar sobre que tipo e qualidade de cuidado, seus filhos irão receber, tendo-se que estes resultados influem negativamente na saúde infantil.

Dados importantes foram detectados no perfil obstétrico, quando todas as adolescentes entrevistadas relataram ter vivenciado a primeira gestaçáo, sendo que, apenas uma teve parto cesariano e nenhuma havia então abortado, contrariando dados estatísticos nacionais, que apresentam percentual elevado de adolescentes grávidas, entre 15 e 19 anos, que já tinham pelo menos um filho, além do número assustador de abortos na mesma faixa etária que, na maioria das vezes, são praticados clandestinamente.

Quanto aos resultados das entrevistas sobre a percepção que as puérperas tinham acerca do pré-natal que vivenciaram, houve resultados, tanto empolgantes, quanto alarmantes. Pois, o trabalho dos profissionais da ESF, foi aprovadamente relatado por todas as mulheres em estudo, assim como a importância das consultas para a promoção/ manutenção da saúde das mães e, principalmente, dos filhos esperados. Contanto, houve um caso em que a assistência ao pré-natal somente teve início no quinto mês de gestação, por falta de informações quanto às suas importâncias, materna, fetal, familiar e social.

O estudo mostrou-nos ser inquestionável a continuidade da atençáo especial dada à adolescência, pois esta fase é a de maior confusão psíquica quanto aos projetos de vida. A falta destes projetos e a baixa freqüência escolar são causas e riscos 
potenciais que levam a adolescente a um estágio de vulnerabilidade, ficando estas, mais propensas à gravidez, que quanto mais precoce ocorrer, mais prejuízo ela trará, tanto para a adolescente quanto para seu bebê, diminuindo as perspectivas de futuro de ambos.

Percebemos que há a necessidade de uma maior informação comunitária sobre os benefícios que a atenção ao pré-natal proporciona às mães e aos futuros filhos, para que todas as mulheres conheçam o verdadeiro propósito do pré-natal, pois, acredita-se que, assim, as gestantes passaráo a priorizá-la, já que ficou repetidamente relatado na pesquisa a grande aceitação dessa assistência pelas adolescentes em estudo, por julgarem ser benéfica para a sua saúde e, principalmente, a de seus filhos.

A família, principalmente na figura dos pais, poderia discutir e orientar seus filhos com relação às dúvidas, angústias, tabus e preconceitos tão freqüentes nessa etapa da vida, entretanto a maioria dos pais tem dificuldade de discutir esses temas em casa com seus filhos adolescentes.

Esta realidade, de origem multicausal, revela deficiências na implementação de políticas públicas, exigindo um movimento do governo e da sociedade para promover a saúde e o desenvolvimento da juventude e permitir que as mulheres adolescentes retomem seu papel econômico, político e social na comunidade e ainda, para que estas, tão jovens e cheias de sonhos, voltem ao colégio e não percam as esperanças de uma vida com mais dignidade.

\section{Referências}

1. Cadete MMM. Da adolescência ao processo de adolescer [tese]. São Paulo: Escola de Enfermagem, Universidade de São Paulo; 1994

2. Saito MI. Adolescência, cultura, vulnerabilidade e risco. A prevenção em questão. In: Saito MI, Silva LEV.
Adolescência: prevenção e risco. São Paulo: Atheneu; 2001. p. 33-38.

3. Ministério da Saúde. Secretaria de Políticas de Saúde. O desafio de construir e implementar políticas de saúde - relatório de gestão. Brasília: Ministério da Saúde; 2002.

4. Ministério da Saúde. Parto, aborto e puerpério: assistência humanizada à mulher. Brasília: Ministério da Saúde; 2003.

5. Gomes R. A análise de dados em pesquisa qualitativa. In: Minayo MCS, ed. Pesquisa social: teoria, método e criatividade. 22a ed. Petrópolis: Vozes; 2003. p. 67-80.

6. Ministério da Saúde. Fundação Nacional de Saúde. Diretrizes e normas reguladoras de pesquisas. Informe epidemiológico do SUS 1996;5(2, supl. 3):1-14.

7. Ministério da Saúde. A adolescente grávida e os serviços de saúde do município. Brasília: Ministério da Saúde; 1999.

8. Instituto Brasileiro de Geografia e Estatística-IBGE. Censo Demográfico 2000: população residente, por sexo e situação do domicílio, população residente de 10 anos ou mais de idade, total, alfabetizada e taxa de alfabetização, segundo os municípios. [citado em 2007 Jan 1]. Disponível em: URL: http://www.ibge. gov.br/.

9. Ministério da Saúde. Assistência pré-natal. Brasília: Ministério da Saúde; 2000a.

10. Ministério da Saúde. Gestação de alto risco. Brasília: Ministério da Saúde; 2000b.

11. Fundo das Naçóes Unidas para a Infância-UNICEF. Situação mundial da infância. New York: Unicef; 2004.

12. Solymos GB. A experiência vivida de mães de desnutridos: um novo enfoque para a intervenção de desnutrição infantil. Psychiatry [online] 1997 [citado 2007 Jan 13];2(36). Disponível em: URL: http://www. psi.org.br.

13. Costa MCO. Fecundidade na adolescência: perspectiva histórica e atual. J Pediatr 1998;74:87-90.

14. Mendes EV, ed. Distrito sanitário: o processo social de mudança das práticas sanitárias do Sistema Único de Saúde. 4a ed. São Paulo: Hucitec; Rio de Janeiro: Abrasco; 1999. 